\title{
Mes profs de gym m'ont appris à penser
}

Michel Serres, Cherche Midi, 2020, 89 p.

\section{Yannick Tenne}

\section{OpenEdition}

\section{Journals}

Édition électronique

URL : https://journals.openedition.org/ries/10016

DOI : 10.4000/ries.10016

ISSN : 2261-4265

Éditeur

France Education international

Édition imprimée

Date de publication : 1 décembre 2020

Pagination : 47

ISBN : 978-2-85420-628-9

ISSN : $1254-4590$

\section{Référence électronique}

Yannick Tenne, «Mes profs de gym m'ont appris à penser », Revue internationale d'éducation de Sèvres [En ligne], 85 | décembre 2020, mis en ligne le 01 décembre 2020, consulté le 07 décembre 2022. URL http://journals.openedition.org/ries/10016 ; DOI : https://doi.org/10.4000/ries.10016

Ce document a été généré automatiquement le 7 décembre 2022.

Tous droits réservés 


\title{
Mes profs de gym m'ont appris à penser
}

\author{
Michel Serres, Cherche Midi, 2020, 89 p.
}

\author{
Yannick Tenne
}

\section{RÉFÉRENCE}

Mes profs de gym m'ont appris à penser, Michel Serres, Cherche Midi, 2020, 89 p.

1 Dans ce court opuscule issu d'un entretien réalisé pour l'Institut national du sport, de l'expertise et de la performance (Insep) en 2009, Michel Serres répond, avec un brin de malice et de facétie, à plusieurs questions sur le sport et ses "professeurs de gymnastique » (sic). Comme il l'indique lui-même, ce livre est à considérer comme un oral et non comme un écrit («Attention: les pages qui suivent font entendre l'oral plutôt que l'écrit »).

2 Le cœur du propos de Michel Serres est de montrer comment le sport, l'activité physique engagent un processus d'humanisation constant. Avec le corps et dans sa relation au monde, la notion de transmission est autre. Il ne s'agit pas de «tout comprendre pour apprendre ${ }^{1} »$ mais de laisser une part d'appropriation intuitive, qui fait que la mémoire de notre corps intègre des schèmes de compréhension qui se dévoileront ultérieurement. La pratique corporelle et sportive devient donc essentielle car « la main peut comprendre avant l'intelligence ». Dans ce parti pris sans concession sur la place du corps, Michel Serres milite pour une autre forme d'enseignement. Les activités physiques doivent avoir une place plus centrale, les «professeurs de gymnastique » être considérés différemment dans leurs apports au développement cognitif et social des élèves.

3 Au-delà de cette approche, ce livre est l'occasion de nombreuses évocations et digressions sur l'évolution de l'homme, l'« érotisme puissant » de la balle ou du ballon, la relation du corps et de la technique. Le philosophe partage donc des réflexions au gré des évocations de l'intervieweur. Ce faisceau d'échanges permet à sa pensée de se définir et d'être partagée, même si l'on peut rester sur sa faim en imaginant l'ampleur que pourraient prendre certaines affirmations. 
4 C'est peut-être le cas avec son analyse de l'arbitrage, où il interroge clairement la gestion de la violence ${ }^{2}$. Il aurait été intéressant de poursuivre l'analyse à partir de constats sur les pratiques sportives actuelles. Est-on sûr que l'arbitrage permette toujours la régulation de la violence? Même l'arbitrage par vidéo est soumis aujourd'hui à un questionnement critique. La limite de l'exercice de l'interview "écrite» se trouve dans cette insatisfaction d'une pensée qui se réduit à des énonciations non développées.

En revanche, et c'est la raison du titre, Michel Serres établit une nette délimitation entre l'éducation physique à l'école et le sport. Il glorifie le rôle des professeurs qui éviteront la tentation de faire des élèves des prodiges du sport mais bien plutôt des êtres pensants dont le bien-être corporel est constitutif de leur évolution. Comme l'énonce François Jarraud, dans sa recension de ce livre, « il nous livre une apologie de l'EPS qui situe ses enjeux: émanciper les jeunes, développer du commun et de l'égalité ${ }^{3}$ ». Rien que pour ce programme, la lecture de ce court récit est à faire.

\section{NOTES}

1. «Les pédagogues croient que l'on n'apprend que ce que l'on comprend. Or, si je n'avais appris dans ma vie que ce je comprenais, je ne saurais pas grand-chose. »

2. «Comment gérer la violence ? [...] Mais le contrat, c'est d'abord le lien social avec le ballon, et ensuite ce sont les décisions juridiques prises par l'arbitre. »

3. Le Café pédagogique, 17 septembre 2020.

\section{AUTEUR}

\section{YANNICK TENNE}

Yannick Tenne est inspecteur général de l'éducation, du sport et de la recherche (IGESR) et membre du comité de rédaction de la Revue internationale d'éducation de Sèvres. Courriel :

yannick.tenne[at]igesr.gouv.fr 